\title{
IMAGINÁRIOS DA INFRAÇÃO JUVENIL: UMA ANÁLISE DE TRÊS TRAJETÓRIAS DA SOCIOEDUCAÇÃO DE MEIO ABERTO
}

\author{
Bruna Rossi Koerich ${ }^{1}$ \\ Fernanda Bittencourt Ribeiro ${ }^{2}$
}

\section{Introdução}

A temática juventude ganhou destaque nos últimos anos tanto na formulação de políticas públicas quanto nos debates acadêmicos, envolvendo um grande mosaico de abordagens e focos (Weisheimer, 2009). Dentre eles, os estudos que se debruçam sobre a intersecção entre juventudes e violências recebem especial atenção da mídia e da sociedade a cada divulgação dos indicadores sociais de violência e criminalidade (Pimenta, 2014).

O Brasil está entre os países com a maior taxa de homicídios entre jovens - de 61 para cada 100 mil jovens em 2014 (IPEA, 2016); e uma das mais crescentes taxas de participação de jovens na população carcerária, chegando a 54,8\% em 2012 (Brasil, 2015). Entendemos que esses indicadores tendem a fortalecer a associação entre juventude e violências bem como a imagem do jovem violento que suscita demandas de endurecimento da política penal e das medidas adotadas pelo sistema de justiça juvenil.

Partindo dessa associação entre a imagem pública de jovem violento e a alternativa penal vista como modo de contenção e punição mais adequada, esse artigo se propõe a analisar quais as imagens que os jovens envolvidos em trajetórias de "criminalidade" fazem acerca de si mesmos, assim como as imagens produzidas sobre eles pelos principais atores sociais envolvidos no cotidiano de um contexto da "socioeducação de meio aberto". Para tanto, apresentaremos dados coletados em trabalho de campo desenvolvido mediante inserção cotidiana em uma unidade socioeducativa de meio aberto localizada no município de Canoas. A particularidade desta pesquisa diz respeito ao fato dos dados terem sido produzidos durante o período

\footnotetext{
${ }^{1}$ Pontifícia Universidade Católica do Rio Grande do Sul, Brasil.

${ }^{2}$ Pontifícia Universidade Católica do Rio Grande do Sul, Brasil.

${ }^{3}$ As medidas socioeducativas de meio aberto são aquelas executadas sem privação total ou parcial de liberdade. As duas principais medidas nessa modalidade são as de Prestação de Serviços à Comunidade (PSC) e de Liberdade Assistida (LA).
} 
de atuação da mestranda como coordenadora do projeto Casa das Juventudes Mathias Velho e Harmonia entre 2014 e $2017^{4}$.

Inspirada na etnografia, ao longo deste período mantive a prática de registrar em diário de campo situações vividas no dia a dia e dados referentes à biografia e trajetória daqueles que circularam por este espaço, na condição de jovens "em cumprimento de medida socioeducativa". Ao longo desta atuação e da realização do curso de graduação em Ciências Sociais pude identificar uma lacuna na produção teórico e metodológica da área, acerca dessa modalidade de atendimento socioeducativo e suas especificidades. Assim, a inserção cotidiana no campo de pesquisa foi sendo tecida nessa dupla prática de supervisionar as atividades e o atendimento dos jovens e este interesse de estudo. Como observa Heredia (2004) acerca de uma condição similar na qual as duas perspectivas - pesquisa e intervenção - coexistiram, para mim também, a diferença entre elas não se colocava tanto no que se refere à maneira de olhar para as questões, ambas orientadas por minha formação em Ciências Sociais, mas principalmente quanto ao tipo de prática que estes "dois lugares" demandam. Nos termos da autora: "por me ver defrontada com situações problemáticas e complexas, diante das quais não poderia fazer o que fazia enquanto pesquisadora: assinalar os prós e contras e tentar descrever os significados que esses fatos têm para os grupos envolvidos e assim analisa-los." (Heredia, 2004: 87).

Através das disciplinas que venho cursando no mestrado em Ciências Sociais, da interlocução em eventos, grupos de pesquisa e com a orientadora, tenho buscado abordar reflexivamente as diferenças e semelhanças entre estes "dois lugares", a fim de qualificar a análise sócio-antropológica dos dados produzidos a partir deles. A definição do tema para a dissertação de mestrado, em torno da construção das projeções de futuro dos jovens, partiu da minha vivência cotidiana nesta prática de intervenção. A partir dela, argumento que a análise dos projetos de futuro jovens constitui-se num produtivo ângulo de visão para a compreensão do complexo fenômeno da violência juvenil.

Uma das especificidades da unidade a que farei referência a seguir é o fato de ser um projeto social de prevenção à criminalidade e a letalidade juvenil no território onde está inserida. A Casa da Juventude Mathias Velho e Harmonia é um projeto da Secretaria Municipal de Segurança Pública e Cidadania, executada pela Fundação La

\footnotetext{
${ }^{4}$ Neste trabalho utiliza-se a primeira pessoa quando se trata da apresentação dos dados e experiência de pesquisa da mestranda. A terceira pessoa será reservada à análise e elaborações textuais resultantes da interlocução com a orientadora e coautora deste artigo.
} 
Salle, e tem como proposta o oferecimento de "atividades de cidadania, de arte e cultura e atendimentos psicossociais para jovens" como estratégias de enfrentamento aos altos índices de violência juvenil na região ${ }^{5}$.

Partindo do entendimento de que o acesso a atividades culturais, esportivas e de formação cidadã podem contribuir para o desenvolvimento de caminhos alternativos à prática criminal, o projeto atende tanto jovens de 12 a 24 anos que estejam em cumprimento de medida socioeducativa, em uma perspectiva de "prevenção terciária" 6 , quanto jovens da mesma faixa etária que apresentam outros "fatores de risco", considerados em "prevenção secundária".

As oficinas de arte e cultura consistem em aulas semanais de violão, percussão, informática, capoeira, hip hop, desenho e comunicação e expressão, onde produz-se rimas, poesias e livros. Nas oficinas semanais de cidadania, os jovens participam de debates sobre temáticas relacionadas à sua realidade, como gênero, juventudes, violências, trajetórias de vida, escolarização, dentre outras. Os atendimentos psicossociais, também semanais, buscam a prática da autorreflexão do jovem sobre a sua realidade.

No município, existem duas Casas da Juventude, inseridas nas duas regiões com os maiores indicadores criminais. Nesse artigo nos referimos à unidade localizada no "território" que compreende os bairros Mathias Velho e Harmonia, que contou com maior proporção de jovens em cumprimento de medidas socioeducativas. A Casa da Juventude Mathias Velho e Harmonia teve duas sedes desde a sua fundação, em 2012. Do início do projeto até o final de 2015, o espaço físico onde as atividades aconteciam caracterizava-se como um galpão, bastante amplo, mas pouco arejado, dividido

\footnotetext{
${ }^{5}$ Com a troca de gestão municipal ocorrida a partir das eleições de 2016, o projeto foi interrompido. Apesar de referir-se à uma política existente apenas no passado, utilizamos o tempo verbal no presente em algumas descrições do campo como forma de reconhecer o presente etnográfico

${ }^{6}$ De acordo com as diretrizes do sistema municipal de prevenção às violências, existem três níveis de prevenção a serem atendidos nas políticas e ações do município: a prevenção primária refere-se à garantia de direitos básicos e ao acompanhamento da população em geral. Para adolescentes e jovens, os equipamentos responsáveis por esse nível de prevenção seriam as escolas e os CRAS - Centros de Referências da Assistência Social; A prevenção secundária atingiria jovens expostos a fatores de vulnerabilização à violência, como estar evadido do sistema formal de ensino; possuir parente ou amigo próximo no sistema prisional, socioeducativo ou vítima de homicídio; e conviver com episódios de violência intradomiciliar. Além da Casa da Juventude, adolescentes e jovens em prevenção secundária são acompanhados pelos CREAS - Centros de Referência Especializado de Assistência Social, pelo Conselho Tutelar e por demais projetos específicos para essa população. A prevenção terciária estaria concentrada na redução dos índices de reincidência socioeducativa e prisional.

${ }^{7}$ São entendidos como fatores de risco marcadores comumente encontrados em jovens vítimas de violência letal como estar em cumprimento de medida socioeducativa, estar evadido do sistema formal de ensino ou possuir familiar ou amigo próximo no sistema prisional.
} 
internamente por divisórias de compensado. Como durante os três anos de funcionamento nesse local, muitos jovens passaram por esse espaço, as divisórias contém várias intervenções juvenis, como dizeres, estênceis, e mesmo desenhos feitos em folhas de papel pendurados por toda parte. Essa sede localizava-se em uma das ruas principais do bairro e chegou a atender 80 jovens simultaneamente.

No início de 2016, o projeto mudou-se para uma região mais particularmente afetada pela violência juvenil, e passou a funcionar em um espaço que fazia jus ao nome de Casa. Esta casa caracteriza-se pela união de dois espaços residenciais justapostos, adaptados para a realidade do atendimento cotidiano das 50 vagas abertas. Os espaços internos da Casa assemelhavam-se ao de uma residência, sendo que um quarto era destinado para a sala da equipe, um para a sala de atendimento, um para a sala de informática, e outro para a sala de música e dança; em uma das cozinhas foi instalado o refeitório, e na outra funcionava a sala de reuniões, onde também eram realizadas as oficinas de desenho e expressão e rima. Na garagem coberta foi instalada a maior sala da Casa, prevista para ser a sala do EJA, que como nunca chegou a funcionar por dificuldades na parceria com a secretaria de educação, era utilizada para as atividades de cine-debate e para os espaços de convivência e socialização gerais. Com exceção da sala de equipe e da sala de atendimento, todos os demais espaços da Casa tinham suas paredes preenchidas pelas produções dos jovens nas oficinas, especialmente nas de desenho.

O projeto previa a convivência total dos jovens "em cumprimento de medidas socioeducativas" e os de "prevenção secundária" e as atividades realizadas por esses dois perfis eram as mesmas. A diferença consistiria no atendimento psicossocial, onde o jovem em cumprimento de medida teria espaços dedicados ao debate sobre a responsabilização do ato realizado. Dessa forma, a previsão era a de que apenas a equipe técnica soubesse quem eram os jovens que estivessem em cumprimento de medida. Contudo, por práticas espontâneas dos jovens, eles acabavam revelando o motivo de sua participação na Casa e acabavam desenvolvendo espaços de socialização distintos nos ambientes do projeto.

Neste artigo apresentaremos três narrativas que consideramos emblemáticas para a compreensão das trajetórias juvenis em contextos de violência e infração. Especialmente em relação às imagens sociais que vão sendo construídas em relação à essas trajetórias trarei algumas informações sobre o local da pesquisa e o projeto do qual 
estes três jovens participaram. Como foco para a análise, traremos dados biográficos de três jovens que cumpriram "medida socioeducativa de prestação de serviços à comunidade $^{8}$ " nesta unidade, explicitando marcas de suas passagens pela Casa em busca de imagens e autoimagens através das quais suas vidas são representadas e vividas.

\section{Juventudes e imaginários sociais}

Utilizar o conceito de imaginário torna necessárias algumas ressalvas acerca de sua polissemia, levando em conta diferentes perspectivas e áreas do conhecimento que o utilizam. Nas suas mais diferentes abordagens, as discussões acerca dos imaginários sociais ganham espaço no ambiente acadêmico devido à sua relevância para a compreensão das sociedades complexas. Conforme alega Espig (2004):

Embora o termo imaginário não seja, por si só, novidade, vem sofrendo resignificações recentemente, no sentido de abarcar uma gama bastante extensa de questões e problemas cada vez mais necessários ao debate acadêmico. (ESPIG, 2004: 49)

Através da noção de imaginário visamos colocar o foco sobre dimensões objetivas e subjetivas, materiais e imateriais (Benjamin, 1985) que permeiam as biografias e os discursos em torno dos jovens "público-alvo" de uma política pública. Conforme Nóbrega:

A noção de imaginário se revela bastante estratégica para que as ciências sociais contemporâneas possam continuar pensando um mundo cada vez mais complexo, em que as certezas passam a ser questionadas, em que as coisas, situações e pessoas não são fixas e mudam cada vez mais rapidamente (Nóbrega, 2015: 8)

Nesse artigo, utilizamos imaginário no sentido de abarcar representações sociais geradas sobre uma parcela específica da população - os jovens autores de atos infracionais - entendendo que essas representações atuam na produção de suas autoimagens.

\footnotetext{
${ }^{8}$ A medida de prestação de serviços à comunidade visa a prática de interesse comunitário, de forma não remunerada, pelos jovens como uma espécie de ressarcimento social pela prática infracional. A legislação é bastante vaga em relação á quais seriam essas atividades. Na Casa da Juventude, a prestação é entendida como a participação nas atividades, com o compromisso de difundir os aprendizados na comunidade.
} 
O imaginário é, pois, representação, evocação, simulação, sentido e significado, jogo de espelhos onde o "verdadeiro" e o aparente se mesclam, estranha composição onde a metade visível evoca qualquer coisa de ausente e difícil de perceber. Persegui-lo como objeto de estudo é desvendar um segredo, é buscar um significado oculto, encontrar a chave para desfazer a representação do ser e parecer (PESAVENTO, 1995: 24).

Nesta perspectiva a construção e negociação de identidades se dá num permanente "jogo de espelhos" (Novaes, 1993) que nos acompanha no decorrer de toda a nossa trajetória de vida. Contudo, autores como Dayrell (2005) argumentam que a juventude é um momento fundamental onde identidades são consolidadas a partir de vivências e experiências. Esse processo de formação e consolidação identitária, visando também os parâmetros de inserção social, seria permeado pela contínua construção e reconstrução de imagens sobre si e sobre os outros. Urcola (2003) defende a possibilidade de falarmos em imaginários sociais dominantes acerca da juventude na sociedade ocidental contemporânea. Para o autor, os imaginários juvenis transitam na convivência e contraposição de dois polos de imagens: de um lado, as imagens referentes à juventude como o futuro da sociedade, e de outro as tensões e problemas sociais decorrentes desse período da vida.

En resumen, la juventud se fue construyendo como representación social de un futuro esperanzador (cuando tomaba el estándar del progreso y el orden establecido) o como futura desdicha y fuente de caos (cuando intentaba transgredir o transformar las pautas y valores socialmente establecidas) en un juego de tensiones y conflictos que van de lo instituido a lo instituyente (Urcola, 2003 : 43)

Nóbrega (2015) aponta uma convivência entre imaginários juvenis ligados a noções de rebeldia e imagens relacionadas à efemeridade. Segundo a autora, podemos observar recentemente um deslocamento de imaginários relativos a engajamentos coletivos para imaginários baseados em valores individualistas. Menandro e Almeida (2003) afirmam que nas imagens atualmente construídas sobre a juventude "predominam interpretações que assinalam características como o consumismo, o individualismo, o conservadorismo, o pouco senso de rebeldia." (2003: 44). 
Além dos imaginários juvenis contemporâneos, cabe observar que os imaginários sociais acerca dos "jovens em cumprimento de medidas socioeducativas" são herdeiros da figura do "menor infrator" que atravessa diferentes períodos históricos.

O imaginário social em torno do "menor infrator" difunde-se a partir da década de 1920 no Brasil, sobretudo através do Código de Menores de 1927. Nesse código, observamos claramente aspectos de uma criminalização da pobreza, e a imagem de que as crianças pobres representam um risco para a sociedade quando fora da família ou do trabalho.

Para cumprir os seus objetivos de "salvar" os jovens órfãos, abandonados e criminosos da delinquência, e de se preservar de ter que lidar no futuro com um adulto criminoso perigoso, o Estado brasileiro tinha à mão diversos mecanismos para mantêlos sob controle, como a tutela, a guarda, a vigilância, a reeducação, a preservação, a moralização e o confinamento (Moreira, 2011).

O chamado novo Código de Menores, promulgado em 1979 também é marcado pela associação entre pobreza e delinquência que preconiza a necessidade de atuação do Estado na tutela dos "menores" expostos à pobreza. A novidade desse marco legal, que sugere uma pequena alteração no imaginário social acerca dessa população, é a formalização da "Doutrina da Situação Irregular". Numa política de culpabilização das famílias pobres predomina a visão de que por "não possuírem competência" para a tutela adequada dos "menores" suas famílias seriam as responsáveis pelo ingresso jovens em trajetórias desviantes. Sobre a chamada Doutrina do Menor em Situação Irregular, Cecília M.B. Coimbra e Lygia S.M. Ayres alegam que:

\begin{abstract}
Por situação de/em risco, definiu-se no novo Código, dentre outras, a incompetência da família pobre, expressa na falta ou carência de recursos financeiros para a manutenção de seus filhos, entendida pelos formuladores da Política Nacional do Bem Estar do Menor (PNBEM), então em vigor, como condição particular de grande parte da população brasileira. Ou seja, como problema meramente individual e não cabia ao Estado responsabilidade sobre o quadro social. A ele, cabia, apenas, a tutela dessas crianças e jovens pobres, à medida que deles as famílias apresentavamse, segundo o modelo proposto no Código, como incompetentes e desestruturadas para tal função social. (Coimbra; Ayres, 2009: 62)
\end{abstract}

No final da década de 1980, muito influenciado pelo contexto de mobilização social e pelas discussões internacionais sobre os direitos de crianças e adolescentes é promulgado o Estatuto da Criança e do Adolescente que até o presente constitui-se no principal marco jurídico sobre a população menor de 18 anos. A promulgação do ECA 
visa marcar ruptura com os paradigmas anteriores. Se até os anos 1990 os textos legais e políticas públicas eram orientados à "questão do menor", agora há uma mudança discursiva e política com a substituição do termo "menor" por "criança e adolescente" (Coimbra e Ayres, 2009). Sob a vigência do Estatuto da Criança e do Adolescente, o reordenamento institucional através do qual se distingue medidas ditas de "proteção" ou de "socioeducação" difunde a noção de crianças, adolescentes e jovens como sujeitos em "condição peculiar de desenvolvimento" em consonância com a Convenção sobre os direitos da criança de 1989. No entanto, apesar da promoção desta concepção universalista de infância podemos observar sua coexistência com a figura do "menor infrator".

Quase três décadas após a adesão formal do Brasil à Doutrina da Proteção Integral, mudanças conjunturais e o aumento da participação de adolescentes e jovens de até 25 anos na criminalidade urbana tem suscitado novos imaginários acerca desses sujeitos. Em uma breve incursão por matérias de jornais, por exemplo, encontramos a circulação de associações entre prática criminal e "falta de limites", tomada como uma característica própria dos adolescentes e jovens de hoje. ${ }^{9}$

(Re)narrar e analisar as três trajetórias a seguir será um modo de aproximação das imagens mobilizadas por (e em relação a) jovens com "envolvimento em ato infracional”. Analisá-las com os referenciais das ciências sociais, tem como objetivo, então, a busca pelo entendimento sobre as concepções que estes jovens têm de si mesmos e como essas concepções são afetadas por imaginários sociais acerca das juventudes.

\footnotetext{
${ }^{9}$ Criminalidade tem relação com "desestruturação familiar" no Brasil. Zero Hora, 16/01/2017; Falta de limites pode levar jovem à criminalidade. Jornal Tribuna Paraná. 13/08/2004; Por que tantos adolescentes estão se envolvendo na criminalidade. Cruzeiro do Vale. 11/03/2011.
} 


\section{Imagens em trajetórias}

Quando falamos em jovens em cumprimento de medida socioeducativa, uma imagem estereotipada do jovem envolvido com o tráfico de drogas é mobilizada quase instantaneamente. $\mathrm{O}$ cotidiano de uma unidade de execução de medidas de meio aberto evidencia, no entanto, uma grande variedade de perfis e uma intensa circulação de imagens que coexistem.

As três trajetórias apresentadas aqui são de jovens com quem convivi durante a realização do campo de pesquisa, e que cumpriam ou já tinham concluído o cumprimento de medida socioeducativa de prestação de serviços à comunidade. Nossas trocas foram permeadas por esse momento específico em que vivíamos eu e eles.

$\mathrm{Na}$ apresentação de suas trajetórias tal como circularam neste espaço, seus nomes e apelidos são trocados a fim de preservar suas identidades e garantir sua segurança. Entre as tantas histórias e trajetórias que pude conhecer estas foram selecionadas por considera-las potentes para a discussão acerca dos imaginários juvenis, pela forte presença de marcadores associados à intersecção entre juventudes e violências e pela multiplicidade de imagens que podem ser encontradas nesses fragmentos biográficos. No decorrer das narrativas que tecem sobre suas trajetórias podemos identificar imagens que os jovens fazem de si mesmos e mesmos as imagens sobre si, produzidas por outros, que eles enunciam e relatam.

\section{Marcos}

A trajetória de Marcos mobiliza, inicialmente, as imagens mais “esperadas” para um jovem em cumprimento de medida socioeducativa. Desde que nasceu, o menino foi criado pela avó porque a mãe "não o quis", como ele fazia questão de dizer. A raiva que sentia da mãe pelo "abandono" não diminuiu a convivência entre os dois, uma vez que moravam no mesmo terreno, junto com as 27 pessoas de sua família.

Com a morte da avó, Marcos - então com 13 anos - ficou sob a responsabilidade de sua mãe, mesmo que preferisse continuar morando com o avô. A distância de três metros que separava uma casa da outra parecia um importante espaço de segurança para o menino. Quando Marcos tinha 15 anos, uma operação policial - com direito à cobertura sensacionalista da mídia local - “encontrou” um ponto de tráfico no terreno 
da família. Nesse dia, foram presos dois adultos e o adolescente, que assumiu toda a mercadoria apreendida como sendo sua. "Eu tinha que cumprir meu papel naquele momento" era o que alegava o jovem que tomou para si a imagem de traficante, que para ele soava como algo heroico.

Sua presença física não passa despercebida nem aos demais jovens, nem à equipe técnica da Casa. Marcos é um jovem alto, com traços que sugerem uma descendência indígena, olhos amendoados e inquietos. Tem um estilo de vestimenta peculiar, priorizando o uso de camisas sempre que possível, graças à sua forte inspiração no pastor de sua igreja. Usa, também, vários acessórios diferentes. Em alguns dias aparece com óculos fingindo ter grau, em outros com um chapéu listrado, outros com um boné chamativo. O fato é que sempre traz consigo elementos que chamam a atenção para si, e parece satisfeito com esse efeito. Tem um ar de malandro, de menino esperto. É bonito e talvez parecesse até mais, não fossem os dentes bastante danificados e o forte cheiro de urina que sempre o acompanhava, decorrente do fato de dividir o único banheiro do terreno com as mais de 20 pessoas que o habitavam.

Com o convívio diário com o jovem, percebi que ele sabia circular por diferentes identidades com destreza, sabendo tirar proveito dessa habilidade. Junto de alguns técnicos, especialmente uma das assistentes sociais que o acompanhou, apresentava uma imagem de vítima, decorrente de sua situação familiar fragilizada e sua vulnerabilidade econômica extrema. Seu processo judicial sugere que também conseguiu mobilizá-la na audiência, convencendo o juiz a conceder-lhe uma medida de prestação de serviços à comunidade, mesmo com a grande quantidade de drogas apreendida no local.

Marcos cumpriu sua medida na unidade nos seis meses previstos e permaneceu frequentando o serviço por mais de dois anos. Nesse tempo, construiu uma imagem de liderança graças a sua presença cotidiana no espaço e de sua capacidade de argumentação, que driblava o problema de dicção e certa dificuldade cognitiva, características de toda a sua família. Essa liderança partia de sua postura, mas era também alimentada pelos demais jovens, em especial os que se encontravam em situação de "prevenção secundária" e viam em Marcos uma maior capacidade de interlocução com a equipe técnica, uma vez que sua permanência de dois anos foi um fator de legitimidade junto a maioria dos técnicos que estavam no projeto a menos tempo que ele. O jovem foi, inclusive, escolhido como orador da turma no momento da 
formatura, ocasião em que apresentou sua história de vida como um processo de superação.

A imagem de "pastor em formação" também é mobilizada pelo jovem com frequência. Seu nome no Facebook, assim como sua foto de perfil - vestido de terno, pregando em um púlpito decorado e com a palavra "Deus" escrito em letras garrafais sugerem uma vida de dedicação à construção desse sonho. Essa inserção carregava consigo atitudes extremadas e preconceituosas. Marcos não conseguia, por exemplo, permanecer no mesmo espaço que jovens fazendo oficina de dança, porque isso era "coisa de mulher".

A relação do jovem com o mundo do trabalho era muito frágil, mesmo que tenha sido a sua justificativa para o abandono escolar, no $5^{\circ}$ ano. Sua capacidade de destaque parecia desestimulá-lo a ocupar uma posição "qualquer" de trabalho. Diversas vezes mencionou que "isso era assunto para depois dos 18 anos", e preferia passar suas manhãs e tardes todos os dias na Casa da Juventude, apesar da pressão familiar que considerava o espaço um lugar de "desocupados e vagabundos" ${ }^{10}$. Marcos permanecia nos espaços da Casa de segunda à quinta, das $8 \mathrm{~h}$ às $17 \mathrm{~h}$, visivelmente transtornado pelo fato de o serviço ter apenas expediente interno nas sextas-feiras. Marcos recebeu, inclusive, uma proposta de trabalho na unidade, que acabou não se efetivando porque não conseguiu juntar a documentação no tempo necessário, em uma posição de auto boicote, segundo avaliação das psicólogas que o acompanhavam na época.

O dia em que sua maioridade chegou foi descrito pelo jovem como o mais triste de sua vida, mesmo que tenha sido eleito representante do projeto no Conselho Municipal da Juventude nesse mesmo dia. As imagens de adulto e responsável pareceram assombrá-lo. Depois de um tempo de ausências na unidade em decorrência dos diversos trabalhos temporários que arrumou, Marcos reapareceu na Casa assumindo a posição que até então conseguia desviar: "agora eu sou bandido" me disse segurando em suas mãos o alvará de soltura dos três meses que passou em prisão provisória no presídio central de Porto Alegre. Acompanhei sua defesa e na visita ao serviço de assistência jurídica universitária, Marcos repetia: "Eu não aprendo mesmo!”, numa atitude de autoflagelo que parecia mais voltada a imagem que queria construir comigo do que algo que falasse para ele mesmo.

\footnotetext{
${ }^{10}$ Segundo relato do jovem, corroborado em conversa com a mãe e a tia de Marcos.
} 
Essa vivência de "nova liberdade" foi interrompida antes de completar duas semanas: Marcos foi preso novamente por tráfico de drogas. Sua imagem de bandido foi estampada na capa do jornal que noticiou sua prisão e o designou como um importante membro do tráfico local, narrando com detalhes o esquema de distribuição da mercadoria. Marcos aparece como figura central na narração de como o "esquema" funcionava. Essa imagem de "X9" 11 que rendeu a figura instantânea de "patrão" lhe custou diversas ameaças para si e para a sua família, algumas das quais pude presenciar.

A última vez que vi Marcos foi em sua audiência. Seu olhar distante e a seriedade em seu rosto me geraram estranheza. Parece que naquele momento Marcos assumia para si o imaginário de jovem violento, que possivelmente vai lhe acompanhar nos próximos anos de privação de liberdade.

\section{Henrique}

Henrique chegou antes em imagem e depois em presença física na unidade de execução onde foi realizada a pesquisa de campo. Vários outros jovens que frequentavam o serviço já haviam falado do "Cabeça" ${ }^{12}$. A imagem de jovem temido e respeitado no local se confirmou nos primeiros dias de convivência. Observei que nos espaços de circulação, todos o cumprimentavam de com um balançar sutil de cabeça, sem olhar diretamente nos olhos, como quem reverencia um superior. No entanto, essa imagem parecia não caber na sua figura física. Era um jovem de 16 anos, estatura mediana, pele morena, um porte levemente atlético, cabelos curtos e escuros, sempre ocultados por um boné que o acompanhava em todas as ocasiões. Aparentemente era um menino, um adolescente como os demais. Mas esta imagem a ele associada era tão forte, que era difícil enxerga-lo como tal.

Uma importante característica sua - o sorriso - demorou algumas semanas para aparecer, mas quando surgiu diversificou os modos de vê-lo: era um sorriso alegre, até meigo, muito diferente da seriedade e da convicção que estampava em seu rosto em todas as vezes que o vi na rua.

\footnotetext{
${ }^{11}$ X9 é uma expressão que designa relator no ambiente criminal. Essa postura costuma ser imperdoável na resolução de conflitos inerente à organização do tráfico de drogas local.

${ }^{12}$ Apelido pelo qual o jovem era conhecido no "território". Este apelido ficcional, escolhido pelo jovem na conversa sobre sua participação na pesquisa.
} 
Henrique tem uma história de vida parecida com a da maioria dos meninos em cumprimento de medida socioeducativa ${ }^{13}$, à exceção do fato de conviver tanto com o pai quanto com a mãe, ambos trabalhadores de um galpão de reciclagem no bairro. Uma das figuras mais importantes da sua trajetória foi o tio paterno, assassinado meses antes da entrada de Henrique na FASE ${ }^{14}$, e que deixou-lhe como "herança", o complexo emaranhado de relações do trafico local.

Henrique nunca teve problema de falar abertamente sobre o seu envolvimento com atos infracionais. Teve uma trajetória importante em um esquema local de roubo e furto de veículos, onde, segundo ele, conseguia tirar a maior parte de seus ganhos financeiros. Gostava também da adrenalina da ação, conforme relatou algumas vezes.

Mas o envolvimento no tráfico de drogas era o que ocupava a maior parte do seu tempo - mesmo sabendo que essas duas "modalidades" de ação infracional devem ser entendidas menos como fatos isolados, e mais como um complexo mosaico de ações. Costumava passar as madrugadas em alguma das bocas ${ }^{15}$, "fiscalizando o turno", como gostava de dizer.

Durante seu atendimento psicossocial semanal, uma das principais ideias trabalhadas era sobre o quanto a sua postura séria e a sua figura temida eram necessárias à sua sobrevivência, mas que, mesmo assim, era preciso pensar em outros marcadores, desejos e sociabilidades que poderiam circular sobre essa vida, onde o "Cabeça", enquanto figura de um "criminoso", era apenas uma das possíveis dimensões.

Com o tempo de convivência, entendi que a Casa da Juventude era um dos poucos lugares onde o Cabeça deixava espaço para o adolescente Henrique, desde a troca de confidências com sua técnica de referência até o inocente jogo de futebol de botão com os colegas nos espaços de sociabilidade.

Existia um grande contraste entre as imagens mobilizados por Henrique dentro da Casa e aquelas acionadas na sua vivência fora desse espaço, mesmo quando esse "fora" refere-se à rua imediatamente em frente da unidade.

\footnotetext{
13 Alguns marcadores são bastante recorrentes nas histórias de vida dos adolescentes em cumprimento de medidas socioeducativas, como a evasão escolar, a vulnerabilidade econômica, a residência em periferias dos grandes centros urbanos e a dificuldade de acesso à alguns de seus direitos básicos.

${ }^{14}$ FASE - Fundação de Atendimento Socioeducativo do Rio Grande do Sul. Henrique esteve 38 dias em internação provisória antes da definição de sua medida de prestação de serviços à comunidade.

${ }_{15}$ Pontos de venda de drogas ilegais que, por vezes, funcionam, também, como espaços de uso e sociabilidades tanto entre os jovens pertencentes ao sistema do tráfico local, como entre usuários.
} 
Certa vez, Henrique não apareceu no horário agendado para as suas atividades. Vários outros jovens também não compareceram para cumprir suas horas de PSC naquele dia, o que levou a equipe a suspeitar que estaria acontecendo algo no território. Fiquei na sala da equipe técnica, onde existe uma grande janela com vista para a rua em que se encontra o portão principal da Casa. No meio da tarde observei um fluxo maior de jovens do que o usual naquela rua e um ritmo mais acelerado que o de costume. Logo a movimentação caracterizou-se como uma "correria" ${ }^{16}$. Dentre vários jovens que vi passando, reconhecendo alguns, notei a figura do Henrique. Tentei notar a sua expressão, mas a velocidade com que passou não me permitiu observar muita coisa, apenas seu rosto sério, com olhar sereno (mesmo que suas pernas em disparada sugerisse uma sensação bem distante da tranquilidade), e o seu movimento preciso em sacar a arma da cintura, com a destreza de quem já conhece muito bem esse movimento, apontando para um grupo de jovens que corria à sua frente. Nesse dia tive dificuldade de relacionar o que via, com a imagem daquele adolescente que poderia estar sentado em minha frente, conversando risonho, caso tivesse aparecido para seu atendimento como esperado.

Em outro episódio, eu estava a caminho da Casa e ao entrar na rua lateral, que dá acesso à unidade, vi Henrique vindo em minha direção. Ele estava acompanhado de uma adolescente, que também devia ter cerca de 15 anos. Ao avistá-lo, senti uma sensação boa ao reconhecê-lo e me preparava para saudá-lo afetuosamente. Quando menos de dois metros nos separavam, percebi que eles começaram a andar mais rápido e Henrique não me cumprimentou ao passar por mim. Sua expressão estava mais uma vez séria, mas nesse episódio havia um tom de preocupação também em seu rosto. Olhei para trás para cobrar o cumprimento, quando vi que a menina começou a gritar para outro adolescente, que saia de uma das casas daquela rua, implorando calma. Observei o menino sair correndo atrás de Henrique, com um revólver em punho e juras de morte. Paralisei por alguns instantes, e logo entrei rapidamente na Casa. Várias motocicletas em alta velocidade começaram a se movimentar para a direção em que Henrique havia corrido, todas pilotadas por adolescentes não mais velhos do que ele. Horas mais tarde, Henrique apareceu na unidade em seu horário normal. Comentei com ele sobre o ocorrido e que temi por sua vida. Ele me disse que estava protegido

\footnotetext{
16 Correria nesse sentido refere-se tanto ao fluxo agitado, quanto a atividades ilegais no território,
} principalmente os momentos onde é necessário o uso de violência ou de fuga. 
(imagino que pelos adolescentes que passaram de moto por mim). Entendi que não me cumprimentar foi uma forma de Henrique me proteger. "Lá fora é selva, dona, tem que se cuidar". Feliz por vê-lo bem e pelo cuidado que teve comigo, passei o restante daquele dia tentando compreender a convivência dessas facetas que mobilizam imagens tão diferentes naquela única vida.

Dias depois, a foto de seu corpo sem vida no chão - entrando para as assombrosas estatísticas de homicídios que acometem a juventude brasileira concretizava o imaginário de jovem violento e perigoso que foi alvejado por um policial que insistia em carregar a imagem de herói. Essas imagens contrastavam com a do garoto, filho amado que partiu e que vieram à tona quando sua mãe me mostrou a certidão de óbito. Com o rosto inchado de chorar e as mãos trêmulas, aquela mulher que aparecia sempre como muito forte nas narrativas de Henrique, aparentava ali uma fragilidade gigantesca. Ela segurava o papel que naquele momento guardava a última imagem de Henrique: um ser humano, um ser orgânico, agora sem vida.

\section{Gabriel}

Gabriel destoa bastante dos perfis mais recorrentes num espaço como a Casa da Juventude. Ele é branco, cabelos loiros, olhos claros e um leve sobrepeso. Usa quase cotidianamente uma calça jeans e uma camiseta de banda de rock progressivo e um tênis estilo all-star ${ }^{17}$, o violão sempre a tiracolo. Uma imagem dócil, de uma ingenuidade quase infantil e uma postura de respeito e gentileza que conquista com facilidade todos os técnicos, educadores e estagiários da unidade.

Sua situação familiar e socioeconômica também o coloca em uma situação diferente da maioria dos meninos acompanhados. Gabriel vive com seus pais numa casa confortável. Sua irmã mais velha mora com o marido e o filho em uma casa construída nos fundos do terreno, não por necessidade, mas para aumentar a convivência familiar. Gabriel hoje está matriculado e frequentando o ensino médio, sua irmã completou ensino superior, o que é uma raridade na região.

\footnotetext{
${ }^{17}$ Bem diferente dos tênis "escamas de peixe", frequentemente usados pelos jovens do território como forma de ostentação.
} 
Sua presença naquele espaço, dada essa imagem de jovem "certinho", causava estranheza àqueles que não sabiam do seu ato infracional: "Ele nem parece guri de medida" 18 é uma frase que ouvi com certa frequência dos oficineiros e estagiários que frequentam o espaço e costumam não saber sobre a trajetória infracional dos adolescentes. A curiosidade era também despertada nos demais jovens em cumprimento de medida que por vezes o olhavam de cima a baixo tentando captar "qual era a dele".

A aparente tranquilidade com que Gabriel relaciona-se risonho com todos, esconde as marcas profundas de seu histórico infracional na construção de uma imagem de si mesmo. "Eu sou um monstro" era o que o menino recorrentemente dizia quando falava sobre o ocorrido. Gabriel abusou sexualmente do sobrinho de dois anos em uma tarde em que ficou encarregado dos cuidados do menino para a família.

Essa imagem parece ser acionada pelo jovem apenas nos espaços de atendimento psicossocial ou nos momentos em que fica a sós com o educador social de violão. Gabriel tem verdadeira paixão por música e compôs algumas letras falando sobre seu dilema interno. Em uma delas, o jovem diz que segue a vida torcendo para que o anjo controle o demônio que vive dentro de si. Nos demais espaços de convivência e interação, essas marcas são escondidas com grande habilidade evitando o estigma de duque ${ }^{19}$ que poderia trazer graves consequências para o adolescente.

Certa vez Gabriel foi pressionado por alguns jovens que queriam saber qual o ato havia cometido. Depois de tentar driblar a pressão e utilizar frases muito frequentemente utilizadas pela equipe técnica e por educadores, como "aqui não interessa quem fez o que", Gabriel logo percebeu que deveria adotar outra estratégia. Adotou para si uma imagem de descontrolado e disse que "perdia a cabeça" quando ficava nervoso. Contou ter brigado na escola e que como a briga saiu do controle, estava respondendo por lesão corporal. Conseguiu mobilizar os recursos para sair dessa situação constrangedora - e mesmo perigosa - com bastante destreza. Não presenciei o jovem ser questionado sobre seu ato infracional nenhuma outra vez depois dessa resposta.

\footnotetext{
${ }^{18}$ Corriqueiramente, "guri de medida" é como os técnicos diferenciam nas conversas internas os jovens que estão em cumprimento de medida socioeducativa dos que estão em prevenção secundária.

${ }^{19}$ Duque é como são chamados os "abusadores" no ambiente socioeducativo. Com frequência, jovens que cumprem medida por conta de atos infracionais como esse precisam ser isolados porque sofrem graves retaliações por parte dos demais jovens em cumprimento de medidas.
} 
Outro fator importante para compreender o fragmento de sua trajetória que representa a sua passagem pela Casa da Juventude é a sociabilidade do jovem nesse espaço. Apesar de a Casa atender o público em cumprimento de medidas e os jovens em prevenção secundária de forma integrada, é mais comum a existência de uma sociabilidade específica entre os jovens "das medidas". Para além da vivência entre pares ser balizada pelo papel do ato infracional na construção de uma identidade juvenil "respeitável", existe um recorte geracional na divisão entre esses dois públicos: os jovens que passaram pelo sistema de justiça juvenil, em geral, apresentam mais marcadores de transição para a vida adulta (ou, ao menos, para uma juventude menos infantil) que os demais, como por exemplo...

Mesmo com uma idade mais compatível com os adolescentes em cumprimento de medidas, Gabriel convivia com mais facilidade com os adolescentes em prevenção secundária, geralmente mais jovens (com 12, 13 ou 14 anos). Essa sociabilidade, por vezes, ocorria às custas de um "curvar-se" a brincadeiras e discussões mais infantis que o convencional para a sua idade, e mesmo para a sua maturidade. Gabriel parece compreender a incompatibilidade de sua trajetória e de seus marcadores, para uma convivência plena tanto com os jovens em cumprimento de medidas, quanto com aqueles em prevenção secundária. Por isso, parece gostar mesmo de estar com os trabalhadores da Casa, sendo facilmente confundido com um integrante da equipe.

Gabriel permaneceu na Casa da Juventude por mais 13 meses depois de concluída sua medida, frequentando o espaço quase que diariamente. Estabeleceu importantes vínculos afetivos, principalmente com a última psicóloga que o atendeu. Para ela, o jovem conta entusiasmado sobre o seu recém-iniciado namoro. Sua empolgação com a nova relação é marcada, contudo, por sua dificuldade em contar sobre seu ato infracional para a namorada. Na visão do jovem, é algo "importante demais" para ela não saber, mas difícil demais de contar. Talvez contar sobre o ocorrido dê visibilidade a uma imagem até então restrita a seu espaço familiar e as instância do sistema de justiça juvenil por onde circulou.

Esse jogo de imagens e autoimagens é operado nessa trajetória de forma relativamente consciente. Ao falar sobre como a sua relação consigo mesmo foi alterada pela execução da medida socioeducativa, o jovem demonstra compreender a particularidade desse espaço no tocante à construção das imagens decorrentes de seu ato infracional: 
As pessoas nunca me amaram de verdade, elas gostam de mim pelo que elas acham que eu sou, uma mentira. Aqui eu consigo ser respeitado como eu sou de verdade, não tenho que me preocupar em fingir ser algo que eu não sou ou não ser algo que eu sou. Aqui eu posso ser eu mesmo. (Gabriel em entrevista realizada em novembro de 2016)

\section{A construção de imaginários nas trajetórias juvenis: reflexões e apontamentos}

Analisar esses três fragmentos de trajetórias nos demonstram, antes de mais nada, que não podemos falar em um único imaginário social que circunda a vida dos jovens no ambiente socioeducativo, mesmo que algumas imagens sejam mobilizadas com mais frequência do que outras.

Cada uma dessas três trajetórias, com suas especificidades, demonstra que existe uma infinidade de imagens passíveis de serem acionadas de acordo com as vivências e experiências dos jovens e de suas famílias. Contudo, podemos observar que existem alguns pontos de convergência nessas trajetórias em relação aos imaginários que mobilizam.

Se partirmos de um imaginário social bastante difundido acerca da juventude, o de "futuro da nação", observaremos que nenhuma das trajetórias abordadas seria facilmente associada a essa imagem. Ao contrário, mesmo que de formas diferentes, a imagem de "problema social" permanece colada na identidade desses jovens ao longo de suas narrativas.

Gabriel é um "problema” porque está inscrito em uma moralidade negativa mesmo para os olhares dos demais jovens presentes no ambiente socioeducativo. Marcos é um "problema" porque sua narrativa de "família desestruturada" parece reservar para ele um futuro já prescrito de violência e criminalidade. O problema de Henrique corresponde ao que está socialmente previsto como o destino provável daqueles cujas ações criminais os levam para um caminho sem volta.

Mesmo em relação ao imaginário de "jovem em conflito com a lei” ou o de "criminoso" ${ }^{20}$, nos modos como estas imagens são vividas. Sobre Gabriel recai uma imagem de irreparável no ambiente socioeducativo, por conta da natureza de seu ato infracional, fato que o jovem tenta driblar com uma postura de quase subserviência às expectativas sociais sobre um jovem.

\footnotetext{
${ }^{20}$ Entendendo que, em vários ambientes, os imaginários que recaem sobre eles é mais o de "menor infrator" ou o de "bandido" do que propriamente o de "jovem em conflito com a lei".
} 
Na história de Marcos, existe uma forte presença da imagem de "vítima social", como se existisse pouco ou nada do próprio jovem no desenho de sua trajetória criminal. A imagem de jovem protagonista, nesse sentido, parece conviver de forma paralela à suas práticas infracionais, não sendo possível nenhum ponto de encontro entre elas. Essa imagem é reproduzida pelo próprio jovem ao construir sua narrativa, alegando diversas vezes que "não consegue" fazer diferente, ou em uma postura de auto-culpabilização, afirmando que "não aprende" com seus erros.

A curta história de vida de Henrique traz consigo o desconforto de nos depararmos com uma trajetória criminal bastante permeada pela escolha. Henrique era bastante consciente das consequências que a sua inserção na criminalidade local poderia trazer, e mesmo assim escolheu aproveitar as vantagens que a vida de "patrão" trazia. Essa postura de decisão contribui para que a imagem de "bandido" colasse em sua narrativa, mesmo depois de sua morte (justificada socialmente por essa marca).

Outro apontamento que emerge da análise desses fragmentos biográficos é o reforço do argumento de que a imagem, enquanto identidade, constrói-se na relação (Dayrell, 2005). Em cada um dos espaços por onde circularam esses jovens, diferentes imaginários sociais são acionados, inclusive por eles próprios.

Como defende Novaes (1993), existe uma relação de interdependência entre a imagem que se faz de si e a imagem que se faz do outro, ou dos vários outros (1993:17). Assim, pensar os imaginários sociais mobilizados por esses jovens na construção de imagens de si mesmo, passa por compreender como esses jovens veem os diferentes atores que marcam suas narrativas durante a execução de sua medida socioeducativa como a família, os amigos, os técnicos, a polícia, os operadores do sistema judiciários entre outros.

Nesse jogo cênico, as diversas imagens possíveis vão sendo representadas num roteiro mais ou menos coerente, mas indissociável do contexto. A representação, nesse sentido, não aparece como uma mobilização consciente e manipuladora, onde um ator consegue interpretar diversos personagens. De acordo com Martins, Trindade e Almeida (2003), representar não significa reproduzir ou duplicar, representar significa reconstruir. Em outras palavras, representar é participar ativamente do processo de construção da sociedade e de si. 
As redes sociais emergem como cenário dessa auto representação, onde as imagens sobre si são escolhidas e compartilhadas para mostrar algo que diga sobre si. Henrique ostentava fotos com armas e dinheiro. Marcos escolhia as imagens relacionadas à suas interações de cunho religioso, mesmo que também tenha uma inserção na trajetória criminal. Entender por que Marcos montava a sua imagem pública (por meio de uma das mais acessadas redes sociais) a partir da religião demanda abordar o papel dessa atividade na construção de si.

As condições sociais contribuem significativamente para esse processo de negociação com as imagens sobre si. Gabriel possui em sua trajetória um marcador carregado de significados negativos mesmo no ambiente socioeducativo. Mesmo assim, consegue com maior destreza que Henrique e Marcos construir uma autoimagem positiva. Acreditamos que o fato de Gabriel ser branco e ter uma escolaridade bastante superior aos demais, chegando ao ensino médio, tenha um papel fundamental nessa capacidade de construção de uma imagem positiva.

Há uma clara diferenciação nas trajetórias de Gabriel em relação às de Henrique e Marcos. Sua posição social permitiu oportunidades bastante diferentes para este jovem que, além da conclusão de sua escolarização, ruma para uma inserção formal no mercado trabalho. Por suas dificuldades em acessar direitos, Marcos e Henrique acabaram tendo suas trajetórias balizadas por marcas mais permanentes como a morte e a inserção no sistema prisional adulto.

Os momentos emblemáticos dessas duas trajetórias - o falecimento de Henrique e a prisão de Marcos - foram reveladores dos imaginários sociais que circundam suas narrativas. Diferentes atores da comunidade local verbalizaram máximas como "um bandido a menos" ou "até que enfim esse bandido teve o que merecia". Nesse sentido, a imagem de bandido demarca um tensionamento com a imagem de sujeito em desenvolvimento apresentada a partir do Estatuto da Criança e do Adolescente, conforme exposto no início desse artigo.

Se a promulgação do ECA desloca apenas parcialmente a imagem de menor infrator para a imagem de sujeito de direitos, uma vez que permanecem concepções de criminalização da pobreza e culpabilização da "família desestruturada"; contemporaneamente observamos uma movimentação dessa imagem remanescente de "menor infrator" para a de "bandido", independente da faixa etária na qual se enquadra o indivíduo. Essa imagem é bastante reforçada por alguns programas midiáticos que 
apostam na construção de um inimigo social como forma intervenção em um fenômeno social complexo e multicausal.

Longe de querer encerrar o debate, esse artigo buscou - ao contrário - apresentar apontamentos e reflexões acerca dos imaginários juvenis e de violência, partindo de fragmentos de trajetórias de três jovens em cumprimento de medida socioeducativa. Nesse caso, as próprias trajetórias juvenis podem ser compreendidas como imagens selecionadas e colocadas em interação por uns e outros: jovens, trabalhadores que atuam no cotidiano "da socioeducação" e pesquisadora. Dessas imagens emergiram reflexões acerca da forma como estes diferentes atores mobilizam diversos imaginários em um jogo constante de encenação, construção e reconstrução de identidades, de acordo com os repertórios disponíveis, demonstrando que o imaginário social acerca da intersecção entre juventude e violência é menos homogêneo do que faz parecer o senso comum sobre a temática.

\section{Referências}

ABRAMOVAY, M., CASTRO, M. G., PINHEIRO, L. C., LIMA, F. S., \& MARTINELLI, C. C. (2002). Juventude violência e vulnerabilidade social na América Latina: Desafios para políticas públicas. Brasília, DF: UNESCO/BID, 2002.

BENJAMIN, Walter. A obra de arte na era de sua reprodutibilidade técnica. In Obras escolhidas: magia e técnica, arte e política. São Paulo: Brasiliense, 1985.

Brasil. Presidência da República. Secretaria Geral. Mapa do encarceramento: os jovens do Brasil / Secretaria-Geral da Presidência da República e Secretaria Nacional de Juventude. Brasília: Presidência da República, 2015. 112 p.: il. - (Série Juventude Viva).

COIMBRA, Cecília; AYRES, Ligia; NASCIMENTO, Maria Livia. Pivetes: encontros entre a $\begin{array}{llllll}\text { psicologia } & e & o & \text { judiciário. } & \text { Curitiba: } & \text { Juruá, }\end{array}$ DAYRELL, Juarez. Por uma pedagogia da juventude. Onda Jovem, São Paulo, n.1, p. 34-47, 2005.

HEREDIA, Beatriz. Algumas reflexões sobre prática acadêmica e prática política. Um antropólogo numa ONG. In: Gláucia Silva (org.), Antropologia extramuros: novas responsabilidades sociais e políticas dos antropólogos. Brasília, Paralelo 15, 2008. p. 87-98.

IPEA - Instituto de Pesquisa Econômica Aplicada. Atlas da Violência 2014. Nota Técnica $n^{\circ} 17$. Brasília, março de 2016.

MALFITANO, Ana Paula Serrata e ADORNO, Rubens de Camargo Ferreira. Infância, juventude e vivências nas ruas: entre $o$ imaginário da instituição $e$ do direito. Imaginário. vol.12, n.12, 2006. p. 15-33.

MARTINS, P.O., TRINDADE, Z.A. \& ALMEIDA, A.M.O. O Ter e o Ser: Representações Sociais da Adolescência entre Adolescentes de Inserção Urbana e Rural. Psicologia: Reflexão e Crítica. n.16 v 3, 2003. p. 555-568.

MENANDRO, Maria Cristina Smith; TRINDADE, Zeidi Araújo e ALMEIDA, Angela Maria de Oliveira. Representações sociais da adolescência/juventude a partir de textos jornalísticos (1968-1974 e 1996-2002). Arquivo Brasileiro de Psicologia 2003, vol.55, n.1, 2003, p. 43-55. MICHAUD, Y. (1989). A violência (L. Garcia, Trad.). São Paulo: Ática. 
MOREIRA, Raquel Ribeiro. Meninos do Cense - as relações de estigmatização, violência e disciplinarização de adolescentes em conflito com a lei, internados. Tese de Doutorado Universidade Federal do Rio Grande do Sul. Porto Alegre, 2011.

NÓBREGA, Thais Zonta de. Imaginários juvenis: cinema, recepção, mediações e consumo cultural. 2015. 182 f. Dissertação de Mestrado - Pontifícia Universidade Católica de São Paulo. São Paulo, 2015.

NOVAES, Sylvia Caiuby. Jogo de espelhos: imagens da representação de si através dos outros. São Paulo: EDUSP, 1993.

PESAVENTO, Sandra. Em busca de uma outra história: imaginando o imaginário. Revista Brasileira de História, São Paulo, v. 15, no 29, 1995.

PIMENTA, Melissa de Mattos. Juventude e Violência. In: LIMA, Renato Sérgio de, RATTON, José Luiz e AZEVEDO, Rodrigo Ghiringhelli de. Crime, polícia e justiça no Brasil. São Paulo: Contexto, 2014, p. 265-276.

SÁ, C. P. (1993) Representações sociais: o conceito e o estado atual da teoria. In: SPINK, M.J. (Org.) O conhecimento no cotidiano: as representações sociais na perspectiva da psicologia social. São Paulo: Brasiliense.

URCOLA, Marcos. Algunas apreciaciones sobre ele concepto sociológico de Juventude. Novembro de 2003. Periódico da Universidade Nacional e La Plata.

WEISHEIMER, Nilson.. Teoria Sociológica das Gerações. In: Universidade Luterana do Brasil. (Org.). Sociologia da Juventude. 1ed.Curitiba: IBPEX, 2009, v. 1, p. 57-75

Recebido em: 29/05/2017. Aprovado em: 03/07/2017. 